\title{
Ventilator-associated pneumonia in a teaching hospital in Tehran and use of the Iranian Nosocomial Infections Surveillance software
}

\author{
Sh. Afhami, ${ }^{1}$ A. Hadadi, ${ }^{2}$ E. Khorami, ${ }^{3}$ A. Seifi ${ }^{3}$ and N. Esmailpour Bazaz ${ }^{1}$
}

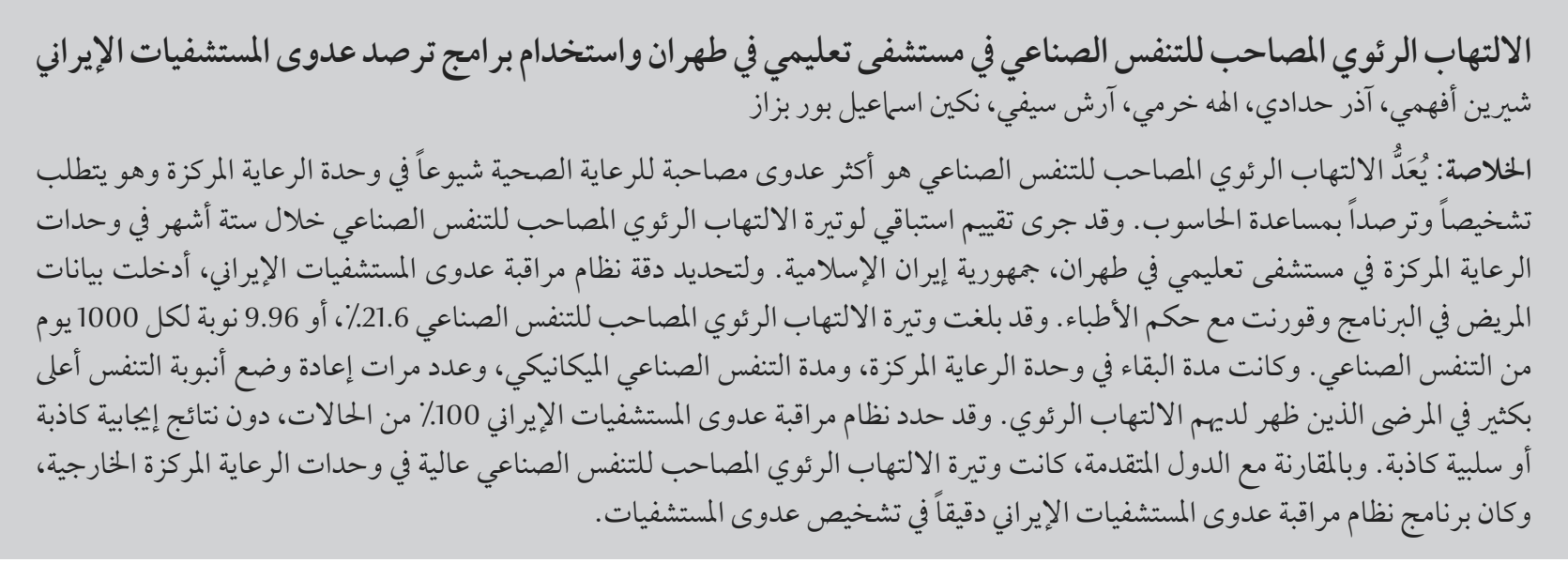

ABSTRACT Ventilator-associated pneumonia is the most common health-care-associated infection in the intensive care unit (ICU) and computer-assisted diagnosis and surveillance is called for. The frequency of ventilator-associated pneumonia was assessed prospectively during a 6-month period in the ICUs of a teaching hospital in Tehran, Islamic Republic of Iran. To determine the accuracy of the Iranian Nosocomial Infections Surveillance (INIS) system, patient data were input to the software and compared with physicians' judgement. The frequency of ventilator-associated pneumonia was $21.6 \%$, or 9.96 episodes per 1000 ventilator days. The duration of admission to the ICU, duration of mechanical ventilator and number of re-intubations were significantly higher in patients who developed pneumonia. The INIS system identified $100 \%$ of cases, with no false-positive or falsenegative results. Compared with developed countries, the frequency of ventilator-associated pneumonia was high in our ICUs, and INIS software was accurate in diagnosing nosocomial infection.

Pneumonie associée à la ventilation mécanique dans un centre hospitalier universitaire de Téhéran et utilisation du logiciel iranien de surveillance des infections nosocomiales

RÉSUMÉ La pneumonie associée à la ventilation mécanique est l'infection associée aux soins la plus courante dans I'unité des soins intensifs et la pose d'un diagnostic et une surveillance assistées par ordinateur sont nécessaires. La fréquence de la pneumonie associée à la ventilation mécanique a été évaluée prospectivement sur une période de six mois au sein d'une unité de soins intensifs d'un centre hospitalier universitaire de Téhéran (République islamique d'Iran). Pour déterminer l'exactitude du système iranien de surveillance des maladies nosocomiales, les données des patients ont été renseignées dans le logiciel et comparées à l'avis des médecins. La fréquence de la pneumonie associée à la ventilation mécanique était de 21,6 \%, soit 9,96 cas pour 1000 jours de ventilation mécanique. La durée du séjour dans l'unité de soins intensifs, la durée de la ventilation mécanique et le nombre d'intubations étaient très supérieurs chez les patients qui avaient contracté une pneumonie. Le système iranien de surveillance des maladies nosocomiales a identifié 100 \% des cas, sans résultats faux-positifs ni faux-négatifs. Par rapport aux pays développés, la fréquence des pneumonies associées à la ventilation mécanique était élevée dans les unités de soins intensifs, et le logiciel utilisé a été exact dans le diagnostic de l'infection nosocomiale.

${ }^{7}$ Department of Infectious Diseases, Shariati Hospital; ${ }^{2}$ Department of Infectious Diseases, Sina Hospital; ${ }^{3}$ Department of Infectious Diseases, Imam Khomeini Hospital, Tehran University of Medical Sciences, Tehran, Islamic Republic of Iran (Correspondence to Sh. Afhami: afhamish@ sina.tums.ac.ir; afhami8@live.com).

Received: 07/05/12; accepted: 15/07/12 


\section{Introduction}

Ventilator-associated pneumonia (VAP), a pneumonia occurring after endotracheal intubation and mechanical ventilation, is the most common health-care-associated infection (HAI) in intensive care units (ICUs) worldwide, with an incidence ranging from $6 \%$ to $52 \%$, even reaching $76 \%$ in some specific settings. It is a major cause of mortality, morbidity and increased financial burden in patients receiving mechanical ventilation $[1,2]$. The mortality rate for VAP ranges from $24 \%$ to $50 \%$, and can reach as high as $76 \%$ in specific settings or when infection is caused by high-risk pathogens [3]. The occurrence of VAP increases the duration of hospital stay by approximately 6 days $[3,4]$, with associated increase in health-care costs [5]. In several countries surveillance of HAI has become an essential part of infection control programmes, especially in the ICU, where the risk of infection is high [6]. Considering the significant impact of VAP, the United States Centers for Disease Control and Prevention (CDC) strongly recommends that surveillance be conducted for bacterial pneumonia in ICU patients who are mechanically ventilated, in order to facilitate identification of trends and for inter-hospital comparisons [7].

The use of computers in hospital epidemiology and infection control is becoming widespread $[8]$ and specialized software can aid in the rapid and accurate diagnosis of HAI and timely initiation of appropriate interventions to decrease the rate of HAI including VAP. Using a computerized data record, a major database load can be saved and transferred rapidly, to enable comparisons of hospitals for both the frequency of HAI and infection control programmes. The Iranian Nosocomial Infections Surveillance (INIS) is a Microsoft Windows-based program with Persian language user interface [9]. The input data include: standard demographic information (name and identifier, age, etc.), length of hospital stay, location in the hospital, admission and discharge diagnoses, surgi$\mathrm{cal} /$ invasive procedures, device utility days (endotracheal tube, intravascular catheter, urinary catheter), laboratory and pharmacy data. The software can analyse the received patient data and then adjust and compare the data with the CDC's criteria's for the diagnosis of HAI [9].

Since surveillance data on the epidemiology of VAP are limited in the Islamic Republic of Iran, a study was conducted for the first time to determine the frequency of VAP and associated factors and to assess the accuracy of the INIS software for the diagnosis of VAP in the ICUs of a teaching hospital in Tehran.

\section{Methods}

\section{Study design}

This observational, prospective incidence study was undertaken during a 6-month period from 2008-09 in the general and neurosurgery ICUs of a teaching hospital in Tehran, Islamic Republic of Iran to assess the incidence of VAP (number of episodes per 1000 ventilation days). This study was approved by the local research and ethics committee, and the need for informed consent was waived in view of the observational nature of the study.

\section{Data collection}

In the first part of the study all patients who received mechanical ventilation were monitored for the development of VAP. Patients admitted to the ICU who did not receive mechanical ventilation were excluded from the study. The demographic data of patients (sex, age, underlying medical disease, etc.), and number of days of ventilation and ICU stay were recorded. Microbiological investigations were performed when indicated clinically.
VAP was defined according to the CDC criteria as the presence of a new or progressive and persistent infiltrate, consolidation or cavitation on chest X-ray after mechanical ventilation, and at least 2 of the following: temperature $>38^{\circ} \mathrm{C}$ or $<36{ }^{\circ} \mathrm{C}$; leukocytosis (leukocyte count $>11000 / \mathrm{mm}^{3}$ or leukopenia $<4000 / \mathrm{mm}^{3}$ ); purulent endotracheal secretions; isolation of pathogenic bacteria from endotracheal aspiration/blood/pleural fluid; and increasing oxygen requirements; and clinical pulmonary infection score (CPIS) diagnostic criteria (based on 6 clinical and laboratory variables: temperature, leukocyte count, volume and purulence of tracheal secretions, oxygenation, chest radiographic findings and presence or absence of positive endotracheal aspiration cultures) $[7,10,11]$. A total score $>6$ out of a maximum of 12 was considered VAP. VAP incidence density per 1000 ventilation days was calculated by: (number of ventilator-associated pneumonia episodes) $\times 1000 /$ (number of ventilator days).

In the second part of the study, the efficacy and accuracy of the computerized surveillance programme was evaluated. The data from patients under mechanical ventilation were entered into the INIS software and this automated system for the detection of VAP was compared against the physicians' judgement

\section{Analysis}

Standard descriptive statistics were used to describe the study population. Continuous variables were compared with the Student $t$-test for repeated measurements. The chi-squared and Fisher exact tests were used to compare proportions. Continuous variables were presented as means and standard deviations (SD) and categorical variables as numbers and percentages. A probability value < 0.05 was considered statistically significant. 


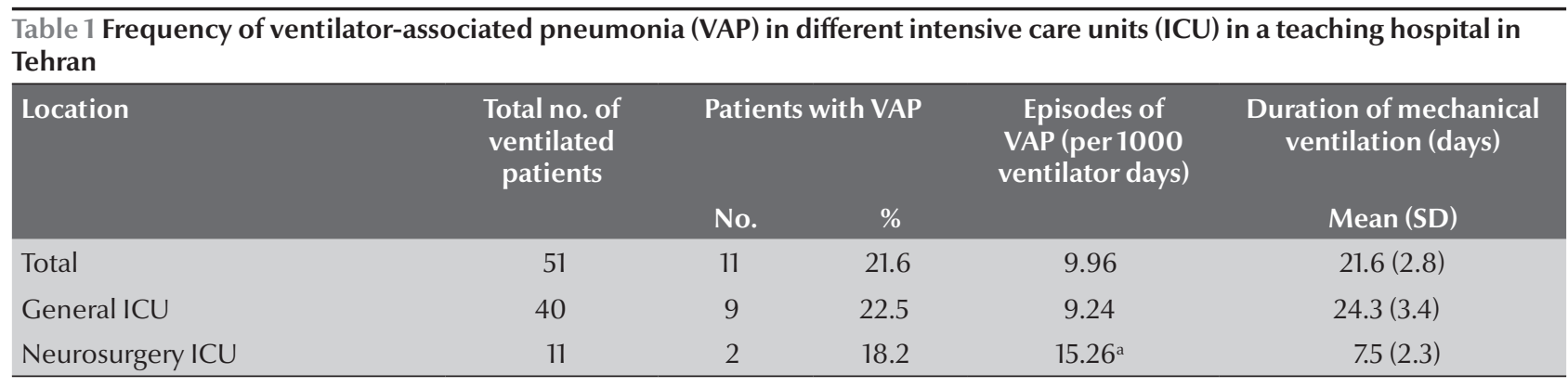

${ }^{a} P=0.76$, neurosurgery ICU versus general ICU.

$S D=$ standard deviation.

\section{Results}

\section{Background data}

During the 6-month study period, 51 eligible patients were monitored for development of VAP; 35 patients (68.6\%) were male, and the mean age of the patients was 52.7 (SD 16.3) years (range: $20-85$ years). Two-thirds of patients $(34,66.7 \%)$ had at least 1 comorbidity. Surgery, trauma and medical problems were the main causes of admission in 33 (64.7\%), 7 (13.7\%) and 11 (21.6\%) patients respectively. The mean length of ICU stay of patients was 23.7 (SD 2.9) days (range: $3-105$ days). The mean duration of mechanical ventilation was 21.6 (SD 2.8) days (range: 3-105 days). The mean number of intubations of each patient was 1.8 (SD 0.13), and 28 patients (54.9\%) were reintubated.

\section{Incidence of VAP and associated factors}

VAP episodes were diagnosed in 11 (21.6\%) patients, and the number of VAP episodes per 1000 ventilator days was 9.96 (Table 1). The mean CPIS score in VAP patients was 8.00 (SD 0.77) (range: 7-9). The mean duration of mechanical ventilation in the general ICU was 24.3 (SD 3.4) days (range: 3-105 days) and in the neurosurgery ICU was 7.5 (SD 2.3) days (range: 3-30 days). Although the number of episodes of VAP per 1000 ventilator days was lower in the general ICU than the neurosurgery ICU (9.24 versus 15.26) the difference was not statistically significant $(P=0.76)$.

The baseline characteristics of the 2 groups of patients with and without VAP are summarized in Table 2 . In patients with VAP, reintubation $(P=$ $0.04)$, the mean number of intubations $(P=0.03)$, mean ICU length of stay $(P=0.002)$ and mean period of mechanical ventilation $(P=0.04)$ were significantly higher than in patients without VAP.

\section{Culture findings}

The cultures from endotracheal aspirates were positive in 10 patients and Staphylococcus aureus was isolated from blood cultures of 1 patient. The

\begin{tabular}{|c|c|c|c|c|}
\hline Variable & VAP + ve $(n=11)$ & VAP -ve $(n=40)$ & $P$-value & $\begin{array}{l}\text { Mean difference } \\
\quad(95 \% \mathrm{Cl})\end{array}$ \\
\hline Mean (SD) age (years) & $59.1(15.2)$ & $51.7(16.6)$ & 0.43 & - \\
\hline Male/female sex ratio & $8 / 3$ & $27 / 13$ & 0.74 & - \\
\hline \multicolumn{5}{|l|}{ Comorbidity (no. \& \% of patients) } \\
\hline Yes & $7(63.6)$ & $27(67.5)$ & 0.81 & - \\
\hline No & $4(36.4)$ & $13(32.5)$ & - & - \\
\hline \multicolumn{5}{|l|}{ Admission diagnosis (No. \& \% of patients) } \\
\hline Trauma & $1(9.1)$ & $6(15.0)$ & 0.80 & - \\
\hline Candidate for surgery & $7(63.6)$ & $26(65.0)$ & - & - \\
\hline Medical problems ${ }^{\mathrm{a}}$ & $3(27.3)$ & $8(20.0)$ & - & - \\
\hline Mean (SD) length of stay in ICU (days) & $40.7(9.8)$ & $19.0(2.2)$ & 0.002 & $21.7(8.5-34.8)$ \\
\hline $\begin{array}{l}\text { Mean (SD) duration of mechanical ventilation } \\
\text { (days) }\end{array}$ & $39.1(9.5)$ & $16.8(1.9)$ & 0.04 & $22.2(0.8-43.8)$ \\
\hline Reintubated (no. \& \% of patients) & $9(81.8)$ & $19(47.5)$ & 0.04 & - \\
\hline Mean (SD) no. of intubations & $2.4(0.2)$ & $1.7(0.1)$ & 0.03 & $0.7(0.1-1.3)$ \\
\hline
\end{tabular}

ancluding diabetes, hypertension.

$S D=$ standard deviation $; C I=$ confidence interval . 
great majority (90.9\%) of VAP cases were caused by Gram-negative bacteria and the most commonly identified organism was Klebsiella spp., isolated from 4 cases, followed by Pseudomonas spp. (3 cases) and Acinetobacter spp. (3 cases). There was 1 case with Escherichia coli and 1 case with polymicrobial VAP (Klebsiella spp. and Pseudomonas spp.)

\section{Treatment and outcome}

The treatment records showed that 6 patients (54.6\%) with VAP received carbapenems antibiotics and 5 (45.4\%) patients were treated with beta lactam/beta lactamase inhibitor drugs (piperacillin/ tazobactam). Vancomycin was administered concomitantly with either of these regimens in $7 / 11(63.6 \%)$ patients.

Among patients who developed VAP, the mortality rate was $45.4 \%$ (5/11 patients).

\section{INIS software}

At the second part of the study, the data collected about ventilated patients with and without VAP as confirmed by infectious diseases physicians were compared with the output of the INIS software. The computer identified all VAP cases (100\%), with no falsepositive or false-negative results in the identification of cases.

\section{Discussion}

At our referral teaching hospital in Tehran, VAP was diagnosed in $11 \mathrm{pa}-$ tients $(21.6 \%)$ and the number of VAP episodes per 1000 ventilator days was 9.96. In our study, most cases of VAP were caused by Gram-negative bacteria, which accounted for $90.9 \%$ of causative organisms. The most commonly identified organism was Klebsiella spp., followed by Pseudomonas spp. and Acinetobacter spp., which is similar to the results of other studies [12-16].

Although the incidence of VAP in our ICU was not as low as the ICUs of developed countries-e.g. 3.3 per 1000 ventilator days in ICUs in the United States [17] — it was lower than the rates reported in many other developing countries - e.g. by Rosenthal et al. in Argentina (46.3 per 1000 device-days) [18], Kanafani et al. in Lebanon (47\%) [12], Memish et al. in Saudi Arabia (25.2\% or 16.8 per 1000 person-days of ventilation) [19], Werarak et al. in Thailand (75.3\%) [13], Rodrigues et al. in Brazil (16.79 per 1000 ventilator days) [14], Joseph et al. in India (18\% or 22.94 per 1000 ventilator days) [15], and the results of the International Infection Control Consortium (INICC) surveillance study in 173 ICUs in Latin America, Asia, Africa and Europe (overall VAP rate of 13.6 per 1000 ventilatordays) [17]. Different incidences of VAP depend on the definition, the type of hospital or ICU, the population studied and the level of antibiotic exposure. The lack of consensus regarding the most appropriate method to diagnose VAP also partly explains why the incidence varies widely from one study to another $[3,15,20,21]$.

The rates of VAP in surgical ICUs have been reported to be higher than in medical ICUs [21], and Rosenthal et al. found a pooled mean VAP rate of $14.7 \%$ (95\% CI: $14.2 \%-15.2 \%$ ) and $25.3 \%$ (95\% CI: $20.9 \%-30.3 \%)$ in medical-surgical and neurosurgical ICUs, respectively [17]. In contrast, our study, there was no statistically significant difference in the incidence of VAP among general and neurosurgery ICU patients, which agrees with the results of Joseph et al. [15].

As other studies $[12,14,19]$, we showed that reintubation, mean number of intubations, mean ICU length of stay and mean period of mechanical ventilation were significantly higher in patients with VAP than patients without VAP.

Information management is integral to clinical practice. Clinicians are information managers, and in day-today practice of medicine they must acquire, process, store, retrieve and apply information. The volume and complexity of patient information has increased dramatically, and this has resulted in a situation where effective clinical information management has exceeded the cognitive capabilities of the human mind. With the availability of admission/ discharge data, laboratory data, pharmacy data and radiology data computerized and integrated, hospital-wide surveillance of nosocomial infections is possible $[8,22]$. In the current study the INIS program identified all VAP cases, with no false-positive or false-negative results, and we conclude that this automated system can be used as a time-saving surveillance method for rapid diagnosis of VAP with minimum human error.

One limitation of this study was that qualitative cultures of endotracheal aspirates was used for detection of organisms, which has lower specificity for the diagnosis of VAP compared with quantitative cultures of respiratory secretions, but the incidence of VAP was not as high in our centre as in some less developed countries, so this could not be a confounding variable. Also, a recent systematic review showed that quantitative culture results are subject to possible sampling variability, and there was no evidence that quantitative cultures, as compared with qualitative cultures, are associated with reductions in mortality, length of the ICU stay, duration of mechanical ventilation or the need to adjust antibiotic therapy [23]. Members of the hospital infection control team should become familiar with data acquisition and analysis on a desktop computer [8]. Compared with developed countries, the frequency of ventilator-associated pneumonia was high in our ICUs, and appropriate surveillance methods are necessary to decrease VAP in ICUs. INIS is an accurate system for diagnosis of VAP.

\section{Acknowledgements}

The authors would like to extend their appreciation to the ICU nurses of Sina Hospital and Miss Rezayi.

Funding: None.

Competing interests: None declared. 


\section{References}

1. Davis KA. Ventilator-associated pneumonia: a review. Journal of Intensive Care Medicine, 2006, 21:211-226.

2. Koenig SM, Truwit JD. Ventilator-associated pneumonia: diagnosis, treatment, and prevention. Clinical Microbiology Reviews, 2006, 19:637-657.

3. Chastre J, Fagon JY. Ventilator-associated pneumonia. American Journal of Respiratory and Critical Care Medicine, 2002, 165:867-903.

4. Safdar N et al. Clinical and economic consequences of ventilator-associated pneumonia: a systematic review. Critical Care Medicine, 2005, 33:2184-2193.

5. Rello J et al. VAP Outcomes Scientific Advisory Group. Epidemiology and outcomes of ventilator-associated pneumonia in a large US database. Chest, 2002, 122:2115-2121.

6. Vincent JL. Nosocomial infections in adult intensive-care units. Lancet, 2003, 361:2068-2077.

7. Tablan OC et al. Guidelines for preventing health-careassociated pneumonia, 2003: recommendations of CDC and the Healthcare Infection Control Practices Advisory Committee. Morbidity and Mortality Weekly Report, 2004, 53:RR-3.

8. Sellick JA Jr. Computers and information management in hospital epidemiology. In: Mayhall CG, ed. Hospital epidemiology and infection control, 2nd ed. Philadelphia, Lippincott Williams and Wilkins, 1999:131-140.

9. Afhami Sh, Hajiabdolbaghi M, Seifi A. [Iran Nosocomial Infections Surveillance Software] [MD dissertation]. Tehran, Islamic Republic of Iran, Tehran University of Medical Sciences, 2004 [In Farsi].

10. Horan TC, Andrus M, Dudeck MA. CDC/NHSN surveillance definition of health care-associated infection and criteria for specific types of infections in the acute care setting. American Journal of Infection Control, 2008, 36:309-332.

11. Pugin J et al. Diagnosis of ventilator associated pneumonia by bacteriologic analysis of bronchoscopic and nonbronchoscopic "blind" bronchoalveolar lavage fluid. American Review of Respiratory Disease, 1991, 143:1121-1129.

12. Kanafani ZA et al. Ventilator-associated pneumonia at a tertiary-care center in a developing country: incidence, microbiology, and susceptibility patterns of isolated microor- ganisms. Infection Control and Hospital Epidemiology, 2003, 24:864-869.

13. Werarak P, Kiratisin P, Thamlikitkul V. Hospital-acquired pneumonia and ventilator-associated pneumonia in adults at Siriraj Hospital: etiology, clinical outcomes, and impact of antimicrobial resistance. Journal of the Medical Association of Thailand, 2010, 93(Suppl. 1):S126-S138.

14. Rodrigues PM et al. Ventilator-associated pneumonia: epidemiology and impact on the clinical evolution of ICU patients. Jornal brasileiro de pneumologia, 2009, 35:1084-1091.

15. Joseph NM et al. Ventilator-associated pneumonia in a tertiary care hospital in India: incidence and risk factors. Journal of Infection in Developing Countries, 2009, 3:771-777.

16. Ahl J et al. Bacterial aetiology in ventilator associated pneumonia at a Swedish university hospital. Scandinavian Journal of Infectious Diseases, 2010, 42:469-474.

17. Rosenthal VD et al. International Nosocomial Infection Control Consortium (INICC) report, data summary for 2003-2008. American Journal of Infection Control, 2010, 38:95-104.

18. Rosenthal VD, Guzman S, Crnich C. Device-associated nosocomial infection rates in intensive care units of Argentina. Infection Control and Hospital Epidemiology, 2004, 25:251-255.

19. Memish ZA et al. The incidence and risk factors of ventilatorassociated pneumonia in a Riyadh hospital. Infection Control and Hospital Epidemiology, 2000, 21:271-273.

20. Niederman MS, Craven DE. Guidelines for the management of adults with hospital-acquired, ventilator-associated, and healthcare-associated pneumonia. American Journal of Respiratory and Critical Care Medicine, 2005, 171:388-416.

21. Alp E, Voss A. Ventilator associated pneumonia and infection control. Annals of Clinical Microbiology and Antimicrobials, 2006, 5:7.

22. Classen DC, Pestotnik SL. The computer-based patient record: An essential technology for hospital epidemiology. In: Mayhall CG, ed. Hospital epidemiology and infection control, 2nd ed. Philadelphia, Lippincott Williams and Wilkins, 1999:141-154.

23. Berton DC et al. Quantitative versus qualitative cultures of respiratory secretions for clinical outcomes in patients with ventilator associated pneumonia. Cochrane Database of Systematic Reviews, 2008, 4:CD006482. 